\title{
Selecting honeybees for worker brood that reduces the reproduction of Varroa destructor
}

\author{
José D. VILLA ${ }^{1}$, Robert G. DANKA ${ }^{1}$, Jeffrey W. HarRIS ${ }^{2}$ \\ ${ }^{1}$ USDA, ARS Honey-Bee Breeding, Genetics \& Physiology Laboratory, 1157 Ben Hur Road, Baton Rouge, LA 70820, \\ USA \\ ${ }^{2}$ Biochemistry, Molecular Biology, Entomology \& Plant Pathology, Box 9655, Mississippi State, MS 39762, USA
}

Received 3 February 2015 - Revised 10 December 2015 - Accepted 3 February 2016

\begin{abstract}
We investigated an effect of Apis mellifera worker brood on the reproduction of Varroa destructor as a resistance trait by conducting seven generations of bidirectional selection. Initial tests showed twofold differences in mite fecundity (progeny per foundress mites) between colonies of different origins. In the first two generations of selection, low and high lines differed significantly in mite fecundity (2.6 vs. 2.9 and 2.3 vs. 2.8), but in five subsequent generations the average values of the low fecundity lines (ranges of 2.7 to 3.3) became indistinguishable from high lines (2.9 to 3.1). Similarly, the relationship between mite fecundity in 117 offspring colonies and in their 26 queen and 22 drone parent colonies was partly significant in the first three generations but not in subsequent generations. These findings suggest that adaptation of mites to host cues, loss of resistance alleles in a small breeding population, or environmental effects present challenges to breeding for this trait.
\end{abstract}

Varroa destructor / selection / honeybee / reproduction / heritability

\section{INTRODUCTION}

Varroa destructor is a serious challenge to beekeeping with Apis mellifera, as evidenced by recent studies of colony mortality in Europe (Genersch et al. 2010; Dainat et al. 2012) and North America (Guzmán-Novoa et al. 2010). Beekeepers have relied primarily on acaricides to protect susceptible colonies worldwide. Predictably, resistance to active ingredients in acaricides develops rapidly (Milani 1999). Other more sustainable complementary approaches may be needed in the future (Dietemann et al. 2012), including the use of bees with genetic resistance. Specific bee-resistance traits show potential in controlling or curbing the growth of mite populations. Hygienic behavior by adult bees with

Corresponding author: R. Danka,

bob.danka@ars.usda.gov

Handling Editor: Peter Rosenkranz specificity towards Varroa-infested brood (i.e., Varroa sensitive hygiene (VSH); Harbo and Harris 2005) can decrease infestations significantly (Harbo and Hoopingarner 1997; Ibrahim et al. 2007; Ward et al. 2008; Danka et al. 2012a). Other traits such as active grooming of phoretic mites (Moretto et al. 1993) and post capping duration of workers (Moritz 1985) are heritable, but there are no clear examples of these traits impacting infestations.

Reduced reproduction of mites in brood is another resistance trait of potential use. Mathematical models indicate that such a single trait would rapidly reduce mite populations in colonies (Fries et al. 1994). Patterns of reproduction of mites in brood of different species and types of honeybees suggest a genetic component in the host that could possibly be used in breeding. In their original host Apis cerana, two closely related mites, Varroa jacobsoni and V. destructor (Anderson and Trueman 2000), reproduce in drone brood but are largely infertile in worker 
brood (Koeniger et al. 1981; De Jong 1988; Anderson 1994; Boot et al. 1997). In contrast, $V$. jacobsoni did not reproduce in either worker or drone brood of A. mellifera (Anderson 1994), while $V$. destructor is generally highly reproductive in brood of both sexes in this new host. Yet there are observations of exceptions to generally high reproduction by $V$. destructor in A. mellifera. Some cases suggest a heritable factor present in the brood of the host that may decrease reproduction of $V$. destructor . These cases include presumably unselected Africanized bees in Brazil through the 1980s and 1990s (Camazine 1986; Rosenkranz and Engels 1994) (but not since then: Garrido et al. 2003), naturally selected European bees in Tunisia (Ritter 1990), Uruguay (Ruttner and Marx 1984), Argentina (Eguaras et al. 1995), Sweden (Locke and Fries 2011), and France (Locke et al. 2012), and bees artificially selected for decreased fertility of mites (Harbo and Hoopingarner 1997) or for lower growth of mite populations in colonies (Emsen et al. 2012).

Chemical cues from host larvae and pupae act as regulators of mite reproduction and suggest potential target mechanisms for breeding efforts. Phoretic female mites maintain their ovaries in a previtellegenic phase (Steiner et al. 1994). After a foundress mite moves into a worker cell prior to capping, semiochemicals from the larva (up to $18 \mathrm{~h}$ after capping) stimulate oogenesis and eventual oviposition (Trouiller and Milani 1999; Garrido and Rosenkranz 2004; Frey et al. 2013). Accordingly, vitellogenins are expressed at highest levels in foundress mites on prepupae (i.e., stretched larvae in cells on days 2-3 post capping; Cabrera Cordon et al. 2013). After vitellogenesis, oviposition by female mites starts 60$70 \mathrm{~h}$ post capping (Steiner et al. 1994). Furthermore, there are factors that can arrest oogenesis after it has initiated, e.g., placing mites with developing ovaries on older pupae (Frey et al. 2013).

We initiated bidirectional selection for an effect of worker brood on mite reproduction because it would be a complement to well-documented, effective, adult-based behavioral mechanisms such as hygiene and grooming. We measured the average fecundity of mites using a standardized protocol that controlled for effects of nursing of brood and source of mites, and eliminated an effect of selective hygienic removal. Three prior studies used similar protocols but produced varying findings. Using procedures where brood source was the main variable and all other factors were controlled, $50 \%$ of the mites in brood from Africanized colonies were fertile (i.e., had produced at least one offspring), while $75 \%$ of those in European bees were fertile (Camazine 1986). The realized fertility of mites (mites that produced likely viable offspring) in brood of sib colonies, while adults were a common mix of adult workers, showed a significant heritability (Harbo and Harris 1999). In contrast, both the fertility and the estimated fecundity (progeny per infested cell) of mites did not differ in grafted brood of offspring colonies propagated from extremes screened in a parental generation (DeGrandiHoffman et al. 2002). In addition to the first two studies suggesting possible genotypic effects, we considered evidence that brood from bees with the trait of SMR/VSH might reduce mite reproduction (Harbo and Hoopingarner 1997, Ibrahim and Spivak 2006, and preliminary tests conducted in 2007 reported here). From 2009 until 2014 we generated seven groups of crosses of queens and drones using instrumental insemination. Parent colonies had been tested and chosen to represent as divergent phenotypes as possible. These propagations allowed us to gauge the effects of bidirectional selection on the trait as well as estimate heritability through time.

\section{MATERIALS AND METHODS}

\subsection{Colony testing}

In 2007, we conducted preliminary tests of techniques with three VSH colonies and three Italian colonies, and found twofold differences in mite fecundity (progeny per foundress mite) with very small variability between colonies in each group (see Section 3). Using the same standardized tests from 2008 to 2014, we tested a total of 149 colonies in a total of 44 trials. For a given trial, the queen in each colony to be tested was placed under a screen cage (ca. $10 \mathrm{~cm} \times 15 \mathrm{~cm}$, queen excluder on top) on an empty comb for $24 \mathrm{~h}$ (range 22 
$26 \mathrm{~h}$ ) on one side and then caged on the other side of the comb for another $24 \mathrm{~h}$. On the fourth day all test combs $(n=5-15)$ were moved to an active brood rearing area above the queen excluder of a common large nurse colony (produced by combining colonies of commercial unselected origins or their supersedures so that adults occupied the equivalent of at least 3 Langstroth deep boxes, with most brood and a queen confined below an excluder). Four days later, test combs were transferred to a common inoculation colony with ca. 10-20 mites per 100 adult bees (similar conformation to the nurse colonies). Prior to introduction of eggs and recently hatched larvae into nurse colonies and of older larvae into inoculation colonies, we removed frames with most of the brood of equivalent ages to the ones being introduced to reduce competition for nursing and for invasion by mites. Four days later, the brood combs were moved to an incubator $\left(34{ }^{\circ} \mathrm{C}\right.$, RH $\left.50-80 \%\right)$ for 57 days, until brood was examined to measure fecundity of mites that infested the brood.

\subsection{Propagations and bidirectional selection}

In 2008, we screened 23 potential parent colonies of varied origins: three VSH, six Minnesota hygienic, four Italian, one Louisiana survivor, and nine more with VSH, Buckfast, or Italian queens instrumentally inseminated with drones from Italian colonies or from survivor colonies from Louisiana or Michigan. These instrumental inseminations did not follow a clear structure, but were done based on availability of queens and drones with the intention of producing highly diverse parental material. In 2012, to add possible new low mite fecundity colonies to the selection, we tested nine colonies from a VSH-derived population with comparatively low levels of Varroa and high levels of infertility (J. Harbo, pers. comm.). From 2009 to 2014, we propagated seven generations of colonies from previously tested low and high colonies from the parental generations or from the previous one or two generations. Queens were instrumentally inseminated with either mixed semen from multiple drones derived from a single queen, or with single drones (second generation of 2009 and 2014). A total of 117 colonies from these propagations yielded sufficient numbers of miteinfested cells to be used in analyses. Two to six colonies were used in each generation as sources of queens, and 1 to 11 daughter colonies from each queen source produced data with adequate sample sizes for analysis. Similarly, in each generation, one to five colonies were used to produce drones and 1 to 24 colonies sired by drones of one queen source produced useful data.

\subsection{Brood infestation and mite reproduction measurements}

Brood cells were examined with stereoscopic microscopes $(10-30 \times)$ for the presence of foundress female mites and their progeny when pupae ranged in development from white with pink eyes to fully tanned bodies with gray wing pads. We assigned infested pupae to development categories (with a close correspondence to days post capping) as follows: pink eyes ( 6 days post capping), purple eyes on white body (seven), tanning on segmental joints (eight), and more complete tanning with either white wing pads (nine) or gray wing pads (ten) (Jay 1962, 1963). The number of foundress mites, the number of progeny, and the categories of progeny (eggs, protonymphs, deutonymphs, and adult males and females) were recorded. Adult progeny female mites were distinguished from adult foundress mites by their lighter tanning and presence of exuviae. The process of caging the queens, nursing and inoculating frames of brood was repeated for each colony to obtain at least 15 singly infested cells in brood evaluations. Colonies with fewer than 15 singly infested brood cells recorded were not used in any analyses.

\subsection{Statistical analyses}

The data collected allowed the calculation of different variables relating to mite reproduction. However, mite fecundity (number of progeny per foundress mite) allows the estimation of means and variances in a colony while incorporating the combined effects of infertility (mites with no offspring), of delayed onset of oviposition (reduced number of offspring at the time of brood evaluations), and of interrupted oviposition. We therefore estimated fecundity for singly infested cells in initial tests of VSH vs. Italian-derived colonies (2007), in potential parent colonies (2008 and 2012) and in seven generations of bidirectional selection (20092014) using mixed model analyses of variance for each of the above nine groupings separately. The model used colony, age of pupae and where appropriate the type of bee (from high or low parents) as fixed effects. The effect of trial (each set of brood frames from different 
queens that simultaneously went through common nursing, inoculation and incubation procedures) was modeled initially as a random effect, but removed from final analyses because it was insignificant.

Linear regressions between average mite fecundities of parent colonies and offspring colonies were calculated using the least square means of mite fecundity for colonies obtained from the analyses of variance described above. Initially, regressions were based on mid-parent values (Falconer 1960). Since data from the first three propagations suggested that maternal inheritance may be stronger, we also analyzed regressions on queen parent and drone parent for each of the seven propagations from 2009 to 2014. Since individual queens or drones were not directly tested, the mean mite fecundity measured in sisters (or supersisters) of the queen heading a colony were considered the queen parent value. Likewise, the drone parent fecundity was estimated from the average of tested sisters (or supersisters) to the queen that produced the drones used to inseminate the queen heading the offspring colony. A total of 117 colonies had corresponding measurements of mite fecundity from 26 queen and 22 drone parents.

\section{RESULTS}

Initial tests in 2007 that separated the effects of brood from other factors, showed that mites reared in brood from colonies selected for suppressed mite reproduction (SMR, now referred to as VSH, Harbo and Harris 2005) had significantly lower fecundity than that of mites reproducing in brood from colonies from an unselected source (1.49 vs. 2.96 progeny per foundress, Figure 1). Colonies of each of the two types had low variation in mite fecundity. Lower fertility of mites (63\% in VSH brood vs. $94 \%$ in unselected brood) and delayed oviposition were the main causes for this reduced fecundity. These initial findings were encouraging, but differences were smaller and more variable in later evaluations of other VSH-derived colonies that same year. A screening of a larger more diverse set of 23 colonies to initiate bidirectional selection in 2008 had a large range in estimated mean fecundity of mites (1.71 to 3.74 mites per foundress, Figure 1).

In the first two generations of bidirectional selection in 2009, colonies derived from crosses of low and high mite fecundity parents showed significant divergence, particularly in the second generation with colonies produced with single drone inseminations (Figure 1). However, starting in 2010, high and low colonies did not differ significantly. This high mite fecundity persisted even when new parents from VSH origins were incorporated into the breeding population in 2012. High and low lines produced very similar mite fecundities in 2013 and 2014 (Figure 1).

The relationship between the fecundity of mites in parental and offspring colonies was similar to the divergence in bidirectional selection in the first two generations (Table I). The slope, $b$, of the relationships between offspring and parents (midparent, and separately, queen and drone parents) ranged from 0.26 to 0.48 (with corresponding $P>$ b ranging from 0.078 to 0.039 ). In the third generation, a very significant association ( $b=0.62, P=0.006$ ) occurred between offspring colonies and measurements on the supersisters of their queen (derived from single drone inseminations). In the subsequent four propagations (20112014) the relationships between parent and offspring colonies were not significant $(P>\mathrm{b}$ ranging from 0.11 to 0.91 ). Despite additional screening, and the use of parents which had tested as quite divergent in mite fecundity (Table I, Figure 1), the average fecundity of mites remained high in 2011-2014, regardless of the fecundity in parent colonies. For example, the mid-parent values for high and low colonies in the first two generations of selection (2009) differed by more than one progeny per foundress while their offspring colonies differed by an average of about half a progeny per foundress. In contrast, the last two propagations had differences in the midparent values between the high and low colonies of similar magnitude (almost 1.5 and 0.3 progeny per foundress) with no corresponding separation between offspring colonies (Table I).

\section{DISCUSSION}

We conducted bidirectional selection of honeybees for a brood-based effect that alters fecundity of Varroa mites. The first two generations of bidirectional selection showed phenotypic differences and evidence for genetically based effects of brood on mite reproduction. High and low lines 


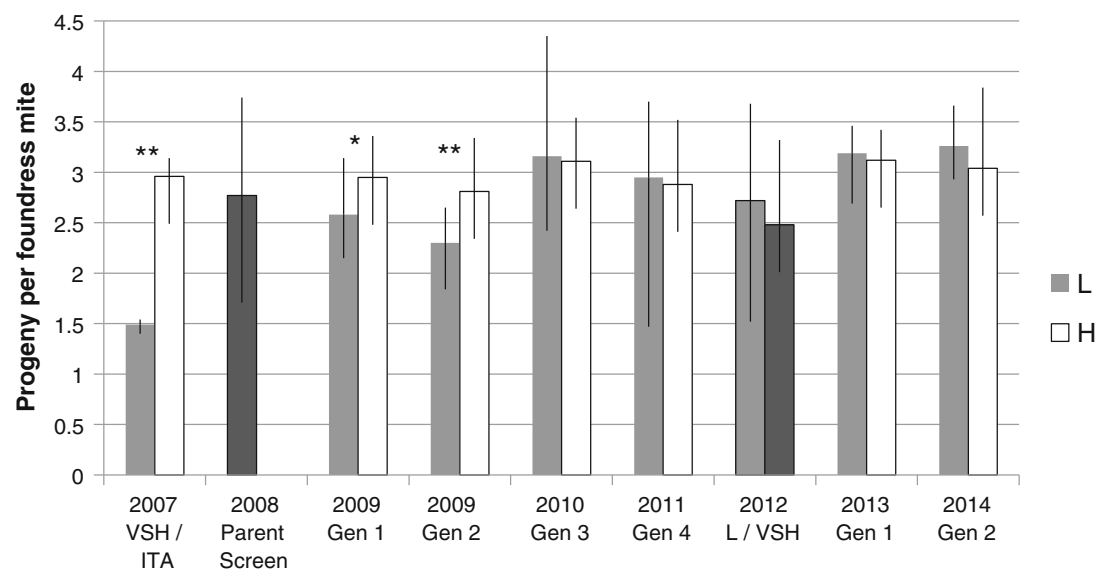

Figure 1. Means of least squares means of mite fecundity (progeny per foundress mite) for colonies tested from 2007 to 2014. Ranges (highest and lowest colony mean mite fecundity in each group) are indicated by lines above and below the bars. The 2007 test compared bees of VSH origins with bees of Italian origin, but these colonies were not used for later propagations. The 2008 test screened 23 colonies of varied origins to select potential parents. Bidirectional selection for low $(L)$ and high $(H)$ lines started in 2009 and continued for four generations. Given the high variability observed within lines, only $L$ colonies plus new VSH colonies were tested in 2012 . In 2013 and 2014, colonies with high values and low values, regardless of origin, were used as parents to generate the $L$ and $H$ groups, respectively. Generation 2 in each bidirectional selection (in 2009 and 2014) was produced with single drone inseminations; all other colonies in other generations of selection were produced with multiple drone inseminations. Numbers of colonies tested are given in Table I. Significant differences between pairs of genotypes are indicated by $*(0.01<P<0.05)$ or $* *(P<0.01)$.

differed significantly in fecundity of mites. Parent-offspring relationships showed positive slopes, some of which had statistical significance. These significant relationships appeared to be stronger via the queen side, suggesting a maternal pattern of inheritance. However, this could also be an artifact of the closer relatedness of phenotyped worker brood to its super or half sisters (used as queens) in the next generation than to the gametes (drones) of queens used to inseminate those queens (Laidlaw and Page 1986). The initial twofold difference in fecundity between Italian colonies and three pure VSH colonies (which had been bred for a number of generations for reduced mite reproduction in brood) was the most striking. Fecundity values are remarkably close to those reported after selection in Ontario for low and high mite population growth in colonies; fecundities of 1.65 versus 3.15 progeny per foundress was the main regulator of mite population growth (Emsen et al. 2012). In our work, however, type (VSH vs. others, 2012) or line (high and low, 2010-2014) differences as well as genotypic effects were not found after the first two years of selection.

Changes in the mite populations or immigration of new mites through time may explain the changed patterns of reproduction in response to colony genetics. Changes from low or no fertility to greater fertility in worker brood have been documented in Asia (D. Anderson pers. comm.) and for Africanized bees in Brazil (Garrido et al. 2003). Moreover, Africanized bees of Central America and Mexico that likely first contacted mites of North American origins did not reduce mite reproduction to the low levels initially seen in Brazil (Medina et al. 2002). The types of mites used to infest test brood could have changed through time in their sensitivity to factors we selected for. Our sources of mites were not homogeneous and isolated. We used mites from available colonies of varied genotypes that had moderate to high infestations at the time of tests. Mites in our apiaries represent locally produced populations maintained purposely with limited or no treatment together with mites from other local 
Table I. Means of least squares means of mite fecundity (progeny per foundress mite) in colonies derived from crosses of previously tested parent colonies in seven propagations.

\begin{tabular}{|c|c|c|c|c|c|c|c|c|c|c|c|}
\hline & \multirow[t]{2}{*}{ Line } & \multirow{2}{*}{$\begin{array}{l}\text { Fecundity } \\
\text { (n colonies) }\end{array}$} & \multicolumn{3}{|c|}{ Mid-parent } & \multicolumn{3}{|c|}{ Queen source } & \multicolumn{3}{|c|}{ Drone source } \\
\hline & & & Fec. & $\mathrm{b}$ & $P>\mathrm{b}$ & Fec. & $\mathrm{b}$ & $P>\mathrm{b}$ & Fec. & $\mathrm{b}$ & $P>\mathrm{b}$ \\
\hline 2009 & $\mathrm{~L}$ & $2.58(9)$ & 2.36 & 0.32 & 0.078 & 2.61 & 0.42 & 0.078 & 2.12 & 0.26 & 0.078 \\
\hline Gen 1 & $\mathrm{H}$ & $2.95(4)$ & 3.55 & & & 3.51 & & & 3.59 & & \\
\hline $2009^{a}$ & $\mathrm{~L}$ & $2.30(6)$ & 2.38 & 0.45 & 0.048 & 2.38 & 0.48 & 0.039 & 2.37 & 0.39 & 0.068 \\
\hline Gen 2 & $\mathrm{H}$ & $2.81(6)$ & 3.46 & & & 3.41 & & & 3.51 & & \\
\hline 2010 & $\mathrm{~L}$ & $3.16(14)$ & 2.63 & 0.44 & 0.120 & 2.69 & 0.62 & 0.006 & 2.56 & 0.02 & 0.920 \\
\hline Gen 3 & $\mathrm{H}$ & $3.12(5)$ & 3.12 & & & 2.91 & & & 3.33 & & \\
\hline 2011 & $\mathrm{~L}$ & $2.95(14)$ & 2.86 & -0.67 & 0.114 & 3.22 & -0.38 & 0.476 & 2.48 & -0.39 & 0.129 \\
\hline Gen 4 & $\mathrm{H}$ & $2.88(5)$ & 3.02 & & & 3.48 & & & 2.57 & & \\
\hline \multirow[t]{2}{*}{2012} & $\mathrm{~L}$ & $2.72(24)$ & 3.05 & -0.09 & 0.827 & 2.54 & -0.04 & 0.827 & 3.57 & ne & ne \\
\hline & VSH & $2.48(9)$ & - & & & - & & & - & & \\
\hline \multirow[t]{2}{*}{2013} & $\mathrm{~L}$ & $3.19(6)$ & 1.85 & 0.02 & 0.801 & 1.95 & -0.01 & 0.913 & 1.74 & 0.05 & 0.546 \\
\hline & $\mathrm{H}$ & $3.12(11)$ & 3.28 & & & 3.61 & & & 2.96 & & \\
\hline \multirow[t]{2}{*}{$2014^{\mathrm{a}}$} & $\mathrm{L}$ & $3.26(5)$ & 2.68 & -0.66 & 0.366 & 2.69 & -0.33 & 0.366 & 2.55 & ne & ne \\
\hline & $\mathrm{H}$ & $3.04(8)$ & 3.01 & & & 3.35 & & & 2.55 & & \\
\hline
\end{tabular}

. The low line (L) was maintained for seven generations, with addition of new colonies in 2012. The high line $(\mathrm{H})$ was maintained for four generations (2008-2010) initially. Later generations of $\mathrm{H}$ derived from colonies with high fecundity. Average mite fecundities for mid-parent (average of queen and drone source), for queen source (fecundity in sisters of queen parent) and for drone source (fecundity of sisters of the queen producing the drones) for each line and propagation are indicated. Additionally, for each propagation, the slope of the regression of offspring colonies from both lines to each of the three parent values (b) and $P>\mathrm{b}$ was calculated. In cases where only one source colony was used, these values are not estimable (ne)

${ }^{\text {a }}$ Single drone inseminated colonies

beekeepers who use acaricides and mites imported from distant areas in our work with cooperating migratory beekeepers. Given this mixed origin of mites, any changes in thresholds to brood cues for oviposition may have occurred independent of our selection program.

Loss of an effect of bee brood on mite reproduction may have also arisen from loss of alleles when working with a narrow genetic population. Available parents were not always the most extreme colonies previously tested due to inevitable colony and queen losses before propagation. This is evident when comparing the range of tested colonies in any generation (Figure 1) with the average of parent values in the following generation (Table I). This issue was not apparent in the first few generations of selection, which supports the hypothesis of a later narrowing of genetic diversity. Even then, introduction of new VSHderived material in 2012 did not improve genotypic differences. Throughout the experiments we did not note overt signs of inbreeding which would have been evident on patches of brood if diminished sex allele frequency led to poor brood viability. Colonies developed and survived similar to other research lines and commercial sources used at the laboratory.

These results suggest that selection for a trait in brood as a defensive mechanism against mite reproduction may be more complicated than we initially thought. The fecundity of mites appears to be influenced at times by brood genotype, but these effects may not be stable. The detection of cues by mites of the optimal age to initiate reproduction may be based on a variable suite of chemicals (Troullier and Milani 1999). Selection would favor continued mite reproduction during this optimal window of late larval honeybee development despite changes in these cues. In a broader context, behavioral social immunity, such 
as hygienic removal of brood and grooming, may be more robust and reliable in contributing to resistance to parasites such as tracheal mites (Acarapis woodi) and Varroa spp. Recent reports of reduced mite reproduction in brood of artificially selected colonies in Canada (Emsen et al. 2012) and of naturally selected colonies in Sweden (Locke and Fries 2011) and France (Locke et al. 2012) may not be due to a direct effect of brood on mites. If capped infested brood is not protected from the selective hygienic behavior of adults, it is not possible to discern the influence of brood from that of adult hygienic activity. Most recent efforts at improving genetic resistance in honey bees of widely diverging origins link the strength of active behavioral defense mechanisms with lower mite populations or mite densities in colonies (Ibrahim et al. 2007; Danka et al. 2010; Guzmán-Novoa et al. 2012; Rinderer et al. 2013).

\section{ACKNOWLEDGMENTS}

Victor Rainey assisted in the propagation, maintenance and testing of colonies. Garrett Dodds performed all of the crosses between colonies using instrumental insemination. Both of them, together with David Dodge and Daniel Winfrey, all with USDA-ARS, helped with evaluations of comb.

Sélection d'abeilles basée sur le couvain d'ouvrières qui réduit la reproduction de Varroa destructor

Acari / Apis mellifera / sélection / reproduction / héritabilité

Selektion von Honigbienen auf Bruteigenschaften, die den Reproduktionserfolg von Varroa destructor reduzieren

Acari / Apis mellifera / Selektion / Honigbienen / Reproduktion / Heritabilität

\section{REFERENCES}

Anderson, D.L. (1994) Non-reproduction of Varroa jacobsoni in Apis mellifera colonies in Papua New Guinea and Indonesia. Apidologie 25, 412-421
Anderson, D.L., Trueman, J.W.H. (2000) Varroa jacobsonii (Acari: Varroidae) is more than one species. Exp. Appl. Acarol. 24, 165-189

Boot, W.J., Tan, N.Q., Dien, P.C., Huan, L.V., Dung, N.V., Long, L.T., Beetsma, J. (1997) Reproductive success of Varroa jacobsoni in brood of its original host, Apis cerana, in comparison to that of its new host, A. mellifera (Hymenoptera: Apidae). Bull. Entomol. Res. 87, 119-126

Cabrera Cordon, A.R., Shirk, P.D., Duehl, A.J., Evans, J.D., Teal, P.E.A. (2013) Variable induction of vitellogenin genes in the varroa mite, Varroa destructor (Anderson \& Trueman), by the honeybee, Apis mellifera L, host and its environment. Insect Mol. Biol. 22, 88-103

Camazine, S. (1986) Differential reproduction of the mite, Varroa jacobsoni (Mesostigmata: Varroidae), on Africanized and European honey bees (Hymenoptera: Apidae). Ann. Entomol. Soc. Am. 79, 801-803

Dainat, B., Evans, J.D., Chen, Y.P., Gauthier, L., Neumann, P. (2012) Dead or alive: deformed wing virus and Varroa destructor reduce the life span of winter honeybees. Environ. Microbiol. 78, 981-987

Danka, R.G., Harris, J.W., Villa, J.D. (2010) Hygienic responses to Varroa destructor by commercial and feral honey bees from the Big Island of Hawaii before exposure to mites. Sci. Bee Cult. 2, 11-14

Danka, R.G., de Guzman, L.I., Rinderer, T.E., Sylvester, H.A., Wagener, C.M., Bourgeois, A.L., Harris, J.W., Villa, J.D. (2012) Functionality of Varroa -resistant honey bees (Hymenoptera: Apidae) when used in migratory beekeeping for crop pollination. J. Econ. Ent. 105, 313-321

De Jong, D. (1988) Varroa jacobsoni does reproduce in worker cells of Apis cerana in South Korea. Apidologie 19, 241-244

DeGrandi-Hoffman, G., Page Jr., R.E., Martin, J., Fondrk, M.K. (2002) Can the frequency of reduced Varroa destructor fecundity in honey bee pupae be increased by selection? Apidologie 33, 563-570

Dietemann, V., Pflugfelder, J., Anderson, D., Charrière, J.D., Chejanovsky, N., et al. (2012) Varroa destructor: research avenues towards sustainable control. J. Apic. Res. 51, 125-132

Eguaras, M., Marcangeli, J., Oppedisano, M., Fernandez, N. (1995) Mortality and reproduction of Varroa jacobsoni in resistant colonies of honey bees (Apis mellifera) in Argentina. Bee Sci. 3, 174-178

Emsen, B., Petukhova, T., Guzman-Novoa, E. (2012) Factors limiting the growth of Varroa destructor populations in selected honey bee (Apis mellifera L.) colonies. J. Anim. Vet. Adv. 11, 4519-4525

Falconer, D.S. (1960) Introduction to quantitative genetics. Ronald Press, New York

Frey, E., Odemer, R., Blum, T., Rosenkranz, P. (2013) Activation and interruption of the reproduction of Varroa destructor is triggered by host signals (Apis mellifera ). J. Invertebr. Pathol. 113, 56-62 
Fries, I., Camazine, S., Sneyd, J. (1994) Population dynamics of Varroa jacobsoni: a model and a review. Bee World 75, 5-28

Garrido, C., Rosenkranz, P. (2004) Volatiles of the honey bee larva initiate oogenesis in the parasitic mite Varroa destructor. Chemoecology 14, 193-197

Garrido, C., Rosenkranz, P., Paxton, R.J., Gonçalves, L.S. (2003) Temporal changes in Varroa destructor fertility and haplotype in Brazil. Apidologie 34, 535-541

Genersch, E., von der Ohe, W., Kaatz, H., Schroeder, A., Otten, C., et al. (2010) The German bee monitoring project: a long term study to understand periodically high winter losses of honey bee. Apidologie 41, 332352

Guzmán-Novoa, E., Eccles, L., Calvete, Y., Mcgowan, J., Kelly, P.G., Correa-Benítez, A. (2010) Varroa destructor is the main culprit for the death and reduced populations of overwintered honey bee (Apis mellifera) colonies in Ontario, Canada. Apidologie 41, 443-450

Guzmán-Novoa, E., Emsen, P., Unger, P., EspinosaMontaño, L.G., Petukhova, T. (2012) Genotypic variability and relationships between mite infestation levels, mite damage, grooming intensity, and removal of Varroa destructor mites in selected strains of worker honey bees (Apis mellifera L.). J. Invertebr. Pathol. 110, 314-320

Harbo, J.R., Harris, J.W. (1999) Heritability in honey bees (Hymenoptera: Apidae) of characteristics associated with resistance to Varroa jacobsoni (Mesostigmata: Varroidae). J. Econ. Entomol. 92, 261-265

Harbo, J.R., Harris, J.W. (2005) Suppressed mite reproduction explained by the behavior of adult bees. J. Apic. Res. 44, 21-23

Harbo, J.R., Hoopingarner, R.A. (1997) Honey bees (Hymenoptera: Apidae) in the United States that express resistance to Varroa jacobsoni (Mesostigmata: Varroidae). J. Econ. Entomol. 90, 893-898

Ibrahim, A., Spivak, M. (2006) The relationship between hygienic behaviour and suppression of mite reproduction as honey bee (Apis mellifera) mechanisms of resistance to Varroa destructor. Apidologie 37, 31-40

Ibrahim, A., Reuter, G.S., Spivak, M. (2007) Field trial of honey bee colonies bred for mechanisms of resistance against Varroa destructor. Apidologie 38, 67-76

Jay, S.C. (1962) Colour changes in honey bee pupae. Bee World 43, 119-122

Jay, S.C. (1963) The development of honeybees in their cells. J. Apic. Res. 2, 117-134

Koeniger, N., Koeniger, G., Wijayagunasekara (1981) Beobachtungen über die Anpassung von Varroa jacobsoni an ihren natürlichen Wirt Apis cerana in Sri Lanka. Apidologie 12, 37-40

Laidlaw Jr., H.H., Page Jr., R.E. (1986) Mating designs. In: Rinderer, T.E. (ed.) Bee genetics and breeding, pp. 323-345. Academic Press, New York

Locke, B., Fries, I. (2011) Characteristics of honey bee colonies (Apis mellifera) in Sweden surviving Varroa destructor infestation. Apidologie 42, 533-542

Locke, B., Le Conte, Y., Crauser, D., Fries, I. (2012) Host adaptations reduce the reproductive success of Varroa destructor in two distinct European honey bee populations. Ecol. Evol. 2, 1144-1150

Medina, L., Martin, S.J., Espinosa-Montaño, L., Ratnieks, F.L.W. (2002) Reproduction of Varroa destructor in worker brood of Africanized honey bees (Apis mellifera ). Exp. Appl. Acarol. 27, 79-88

Milani, N. (1999) The resistance of Varroa jacobsoni Oud. to acaricides. Apidologie 30, 229-234

Moretto, G., Gonçalves, L.S., De Jong, D. (1993) Heritability of Africanized and European honey bee defensive behavior against the mite Varroa jacobsoni. Rev. Bras. Genet. 16, 71-77

Moritz, R.F.A. (1985) Heritability of the postcapping stage in Apis mellifera and its relation to varroatosis resistance. J. Hered. 76, 267-270

Rinderer, T.E., De Guzman, L.I., Frake, A.M. (2013) Associations of parameters related to the fall of Varroa destructor (Mesostigmata: Varroidae) in Russian and Italian honey bee (Hymenoptera: Apidae) colonies. J. Econ. Entomol. 106, 566-575

Ritter, W. (1990) Development of varroa mite populations in treated and untreated colonies in Tunisia. Apidologie 21, 368-370

Rosenkranz, P., Engels, W. (1994) Infertility of Varroa jacobsoni females after invasion into Apis mellifera worker brood as a tolerance factor against varroatosis. Apidologie 25, 402-411

Ruttner, F., Marx, G. (1984) Beobachtungen über eine mögliche Anpassung von Varroa jacobsoni an Apis mellifera L. in Uruguay. Apidologie 15, 43-62

Steiner, J., Dittman, F., Rosenkranz, P., Engels, W. (1994) The first gonocycle of the parasitic mite (Varroa jacobsoni $)$ in relation to preimaginal development of its host, the honey bee (Apis mellifera carnica). Invertebr. Reprod. Develop. 25, 175-183

Trouiller, J., Milani, N. (1999) Stimulation of Varroa jacobsoni Oud. oviposition with semiochemicals from honeybee brood. Apidologie 30, 3-12

Ward, K., Danka, R., Ward, R. (2008) Comparative performance of two mite-resistant stocks of honey bees (Hymenoptera:Apidae) in Alabama beekeeping operations. J. Econ. Entomol. 101 , 654-659 